\title{
Laboreal
}

Volume 17 №2 | 2021

Trabalho e Território

\section{La urdimbre social en la producción del espacio de los mercados de trabajo en la industria de Cochabamba-Bolivia}

O tecido social na produção do posto de trabalho na indústria CochabambaBolívia

Le tissu social dans la production de l'espace du marche de travail dans

l'industrie de Cochabamba-Bolivie

The social fabric in the production of labor market space in the industry of Cochabamba-Bolivia

Tania Aillón Gómez

\section{OpenEdition}

\section{Journals}

Edición electrónica

URL: https://journals.openedition.org/laboreal/18509

DOI: $10.4000 /$ laboreal. 18509

ISSN: 1646-5237

Editor

Universidade do Porto

Referencia electrónica

Tania Aillón Gómez, «La urdimbre social en la producción del espacio de los mercados de trabajo en la industria de Cochabamba-Bolivia», Laboreal [En línea], Volume 17 N² | 2021, Publicado el 03 diciembre 2021, consultado el 05 diciembre 2021. URL: http://journals.openedition.org/laboreal/ 18509 ; DOI: https://doi.org/10.4000/laboreal.18509

Este documento fue generado automáticamente el 5 diciembre 2021.

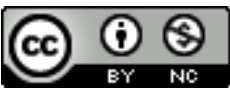

Laboreal está licenciado com uma Licença Creative Commons - Atribuição-NãoComercial 4.0 Internacional. 


\title{
La urdimbre social en la producción del espacio de los mercados de trabajo en la industria de Cochabamba-Bolivia
}

\author{
O tecido social na produção do posto de trabalho na indústria Cochabamba- \\ Bolívia \\ Le tissu social dans la production de l'espace du marche de travail dans \\ l'industrie de Cochabamba-Bolivie \\ The social fabric in the production of labor market space in the industry of \\ Cochabamba-Bolivia
}

Tania Aillón Gómez

\section{NOTA DEL EDITOR}

Manuscrito recibido en : 07/06/2021

Aceptado tras peritaje : 08/09/2021

\section{La aproximación a nuestro objeto de estudio}

A partir de información empírica sobre la configuración de los mercados de trabajo en la industria y de las trayectorias laborales de obreros y obreras, en la región metropolitana de Cochabamba-Bolivia [1], se busca explicar y comprender a los mercados de trabajo de la industria regional, como espacios producidos socialmente, desde una perspectiva epistemológica que ve al espacio como una dimensión relacional (Pattaroni, 2016), que es a la vez, premisa y resultado de prácticas sociales (Kosik, 1963/1990). Un espacio que se origina en prácticas sociales preñadas del sentido y de la 
significación que le dan los trabajadores, pero que emerge ; también, de una situación social dada, que los posiciona como obreros, como migrantes, como mujeres o varones, como jóvenes, etc.

Desde esta perspectiva, tomamos como hilo conductor de nuestro análisis, a las trayectorias laborales, entendidas como un proceso caracterizado por el paso entre diferentes actividades o tareas a lo largo de la vida (que pueden cambiar de dirección) (Hughes, in Tripier, 1998), como cadena de alternativas, que sintetiza procesos estructurales e historias personales y familiares, que se objetivan en configuraciones espaciales. De esta manera, en países como Bolivia, las trayectorias laborales se encastran en la disolución permanente de las formas parcelarias de producción en el agro y en la dinámica de acumulación del capital industrial, ligada a la atracción y expulsión de trabajadores en los mercados de trabajo en el espacio urbano.

1 En consecuencia, el desafío de nuestra exposición, radica en entrelazar los procesos sociales generales, con las trayectorias laborales de trabajadores y trabajadoras, para explicar y comprender la formación espacial de los mercados de trabajo, como espacios producidos socialmente. Se trata de realzar el papel constitutivo de las trayectorias laborales en este proceso de configuración espacial, en consideración a que han sido vistas, principalmente, desde la dimensión temporal que ellas revelan, quedando la dimensión espacial desdibujada a causa de la escasa relevancia analítica que se le ha otorgado (Segura, 2006).

2 Por esto, la primera parte de nuestro trabajo, entrelaza los rasgos estructurales de la formación económico-social de Bolivia, con la dinámica migratoria que permite esbozar el perfil de los obreros de la industria regional. En una segunda parte, se describen las trayectorias laborales de los obreros, con la configuración espacial de los mercados de trabajo de la industria regional, donde se objetiva el tránsito de estos trabajadores, desde el espacio rural al urbano o dentro de éste, desde las zonas de expansión urbana, hasta los barrios obreros y de concentración industrial.

3 Nuestra metodología de obtención de la información, ha combinado los enfoques cualitativo y cuantitativo. En el caso del enfoque cualitativo, se aplicó una entrevista cualitativa en profundidad a informantes clave, elegidos entre trabajadores de la industria regional en sus ramos más representativos (alimentos, textiles, bebidas y curtiembres) ; trabajadores de ambos sexos, con una edad que oscila entre los 20 y los 55 años, y una antigüedad en la empresa de entre 3 y 20 años; trabajadores ubicados en distintos puestos dentro de la estructura de ocupaciones de su empresa. La realización de entrevistas abarca los años 2014 y 2015, con periodos de intervalo de hasta 2 meses. Para el análisis y sistematización de la información obtenida mediante entrevistas, se utilizó el software libre SONAL. El trayecto laboral narrado por los entrevistados, marca los hitos que sirven para la selección de los extractos de las entrevistas, desde su arribo a la ciudad o el arribo de sus padres, siguiendo el sendero que delimita sus diferentes formas de inserción laboral, hasta que se constituyen en trabajadores estables de la empresa donde los encontramos. Otros criterios de selección de extractos de las entrevistas, tienen que ver con el origen rural o urbano de los trabajadores o con su condición de ser hombre o mujer.

4 En el caso del enfoque cuantitativo, se utilizó una encuesta cuya aplicación se basó en un diseño muestral, donde el universo estuvo formado por la población total de obreros y obreras que trabajan en la industria de alimentos, bebidas, textiles y curtiembres en la región metropolitana de Cochabamba (municipios de Cercado, Sacaba, Quillacollo, 
Colcapirhua, Tiquipaya, Vinto y Sipe Sipe) [2]. Para la aplicación de la encuesta se utilizó un muestreo de tipo probabilístico asumiendo que los distintos elementos que componen el universo del estudio tienen la misma probabilidad de ser elegidos. El muestreo estratificado con fijación proporcional por ramo industrial, nos permitió obtener una muestra ajustada al número de trabajadores por cada ramo [3].

\section{Los rasgos de la formación socioeconómica de Bolivia}

Desde nuestra aproximación metodológica, las trayectorias laborales alcanzan un mayor potencial explicativo y comprensivo, si se engarzan con dinámicas socioeconómicas que están más allá de las decisiones personales o familiares, considerando como Harvey (1996/2018), que decir que algo es socialmente construido, no es decir que es personalmente subjetivo; sino que es el resultado de dimensiones con distintos estatutos ontológicos. De ahí que, en este apartado, se introduzcan algunas dimensiones explicativas necesarias para comprender el decurso que siguen las trayectorias laborales de nuestros entrevistados.

\section{La persistencia de la acumulación originaria de capital [4] y la formación de una población excedente o sobrepoblación [ [5]}

En Bolivia no se completó la transformación capitalista en grandes espacios de su formación social ; de ahí que la acumulación originaria forme parte de la dinámica continua de reproducción del capitalismo. Grandes espacios agrarios están formados por minifundios no capitalistas de producción (economía parcelaria) ; prácticamente, el $58.9 \%$ de las unidades agropecuarias en Bolivia son pequeñas explotaciones, que no llegan ni a las 5 hectáreas de extensión (Cuadro 1). Se trata de formas parcelarias de producción, que se convierten en expulsoras de fuerza de trabajo, a medida que se tornan improductivas e insuficientes para sustentar a la familia campesina. 
Cuadro 1 : Bolivia : Unidades Productivas Agrupecuarias por Tamaño de las explotaciones (en ha)

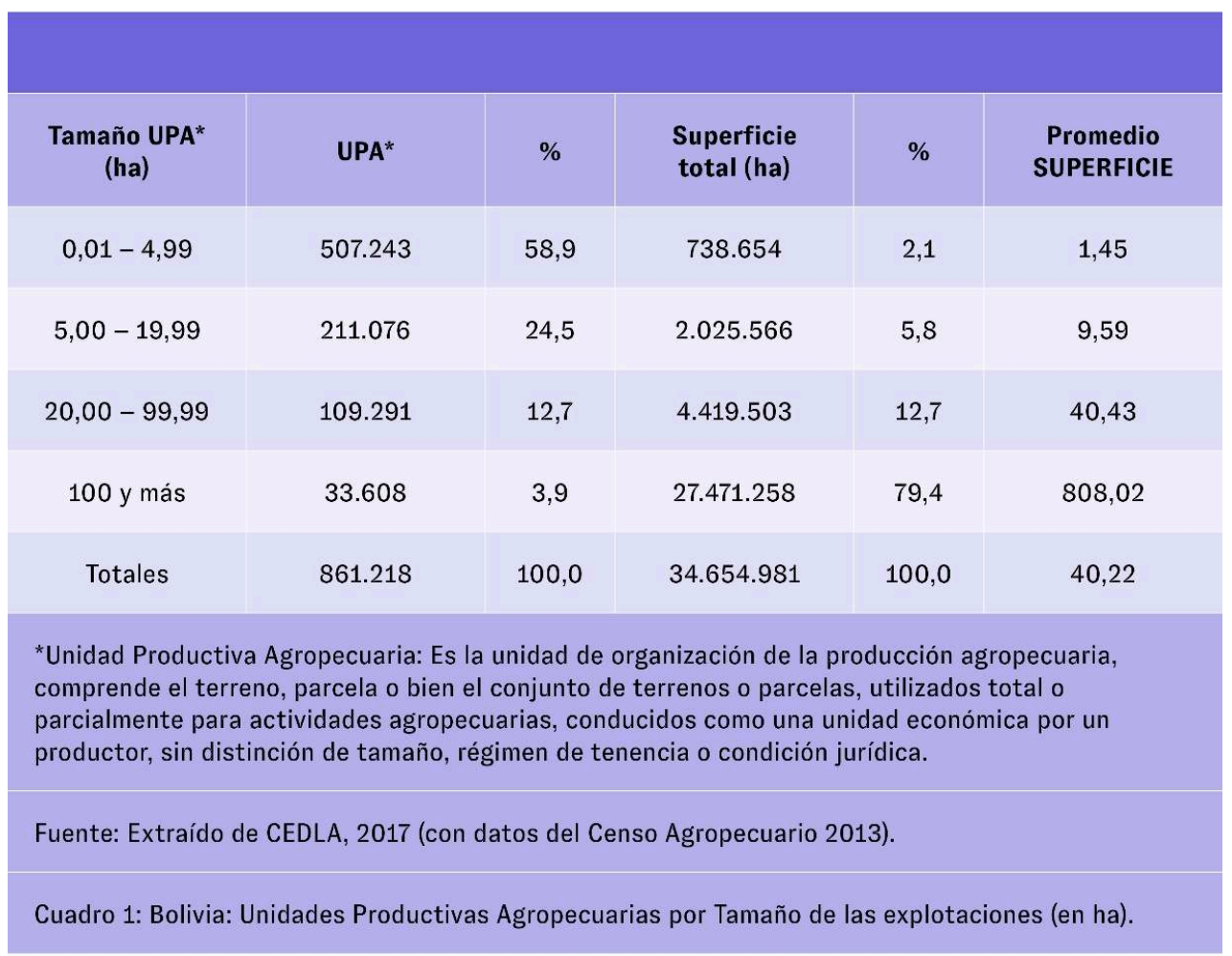

Cuadro 1 : Bolivia : Unidades Productivas Agrupecuarias por Tamaño de las explotaciones (en ha)

Otro rasgo importante a resaltar de la estructura agraria en Bolivia es la importante concentración de tierra que la caracteriza; de acuerdo a la información previa, 507.243 UPAS (Unidades Productivas Agropecuarias) con una extensión de entre 0,01 y 4,99 hectáreas concentran el $2.1 \%$ de la superficie total agrícola, mientras que solo 33068 UPAS, con una extensión de entre 100 y más hectáreas concentran el $79.4 \%$ de la superficie agrícola total.

El hecho de que la acumulación de capital se realice en consonancia con la acumulación originaria de capital, que provoca la expulsión continua de trabajadores campesinos, sin un aparato productivo capaz de absorber fuerza de trabajo expulsada, a procesos productivos capitalistas, crea una significativa sobrepoblación relativa, que siempre está dispuesta a vender su fuerza de trabajo. Este rasgo marca los límites y los alcances de la propia acumulación de capital, a la vez que explica las características de los mercados de trabajo en este tipo de países.

Diferentes estudios concuerdan en señalar, que no es atractivo ser productor agrícola en regiones deprimidas de montaña y valles en las que las condiciones de vida son adversas, no sólo por la ausencia de servicios públicos (caminos vecinales, energía eléctrica, agua potable, educación y salud), sino también, por las extremas condiciones climáticas, frecuentes heladas y sequías, de ahí que la mayoría de los jóvenes emigre a los centros urbanos buscando mejores condiciones de vida, abandonando las pocas tierras que recibió de sus padres (Urioste, 2003).

Cuadro 1 : Bolivia : Unidades Productivas Agrupecuarias por Tamaño de las explotaciones (en ha) 
Cuadro 2 : Departamento de Cochabamba. Incremento absoluto promedio anual de población por regiones, según área rural-urbana (2001-2012)

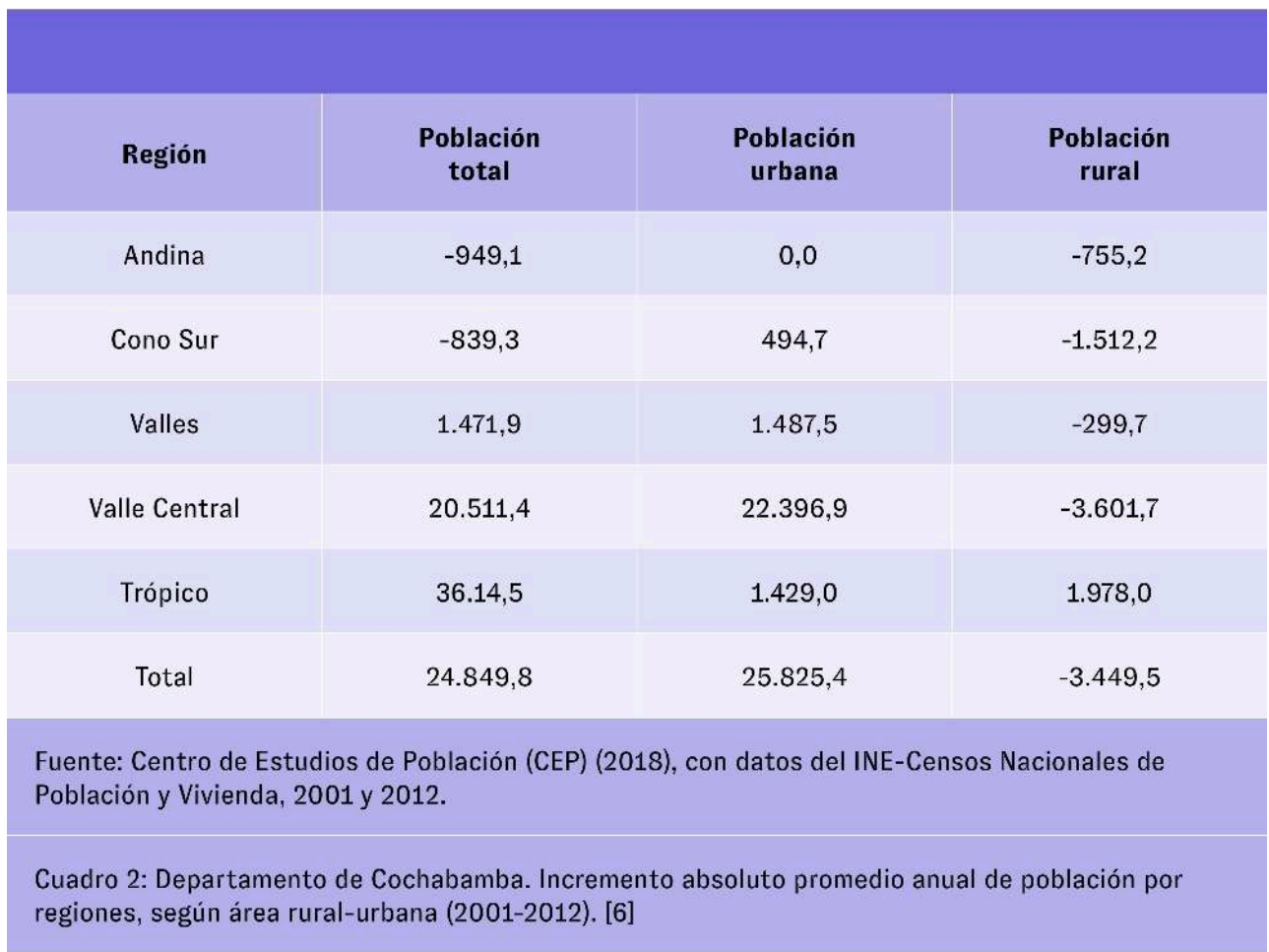

Cuadro 2 : Departamento de Cochabamba. Incremento absoluto promedio anual de población por regiones, según área rural-urbana (2001-2012). [6]

En los datos previos (Cuadro 2), un indicador de la disolución de las formas parcelarias de producción en el agro, es el persistente proceso de urbanización, con la consecuente disminución de las poblaciones rurales, en la mayoría de las regiones del Departamento de Cochabamba. Esta urbanización permanente, que muestran los datos intercensales del cuadro 2, es el resultado de una población excedente en el área rural, que viene a la ciudad, en busca de un ascenso económico-social. La movilidad intrarregional de la población en el Departamento de Cochabamba, como se ve en la siguiente información, es otro indicador en este sentido. 
Cuadro 3 : Departamento de Cochabamba (2001-2012). Cambio en los indicadores de migración por regiones (diferencias simples)

\begin{tabular}{|c|c|c|c|c|}
\hline Región & $\begin{array}{l}\text { Tasa de } \\
\text { inmigración }\end{array}$ & $\begin{array}{l}\text { Tasa de } \\
\text { emigración }\end{array}$ & $\begin{array}{l}\text { Tasa de } \\
\text { migración } \\
\text { neta }\end{array}$ & $\begin{array}{l}\text { Indice de } \\
\text { efectividad } \\
\text { migratoria }\end{array}$ \\
\hline Región Andina & $-0,2$ & 7,9 & $-8,0$ & $-0,2$ \\
\hline Cono Sur & $-1,1$ & 9,5 & $-10,6$ & $-0,2$ \\
\hline Región Valles & 2,8 & $-3,8$ & 6,5 & 0,3 \\
\hline Región Metropolitana & $-6,8$ & $-8,8$ & $-2,0$ & 0,2 \\
\hline Región Trópico & $-6,3$ & 3,1 & $-9,4$ & $-0,2$ \\
\hline Resto del país & $-0,7$ & $-0,1$ & $-0,7$ & $-0,2$ \\
\hline Promedio & $-2,3$ & 1,6 & $-3,9$ & $-0,03$ \\
\hline \multicolumn{5}{|c|}{$\begin{array}{l}\text { Fuente: Centro de Estudios de Población (CEP) (2018), con datos del INE-Censos Nacionales de } \\
\text { Población y Vivienda, } 2001 \text { y } 2012 .\end{array}$} \\
\hline \multicolumn{5}{|c|}{$\begin{array}{l}\text { Cuadro 3: Departamento de Cochabamba (2001-2012). Cambio en los indicadores de migración por } \\
\text { regiones (diferencias simples). }\end{array}$} \\
\hline
\end{tabular}

Cuadro 3 : Departamento de Cochabamba (2001-2012). Cambio en los indicadores de migración por regiones (diferencias simples)

La información del Cuadro 3, muestra a la región metropolitana, donde se asienta la ciudad de Cochabamba, como importante polo de atracción del flujo migratorio intrarregional, con un índice de efectividad migratoria positivo, mientras que las regiones Andina y del Cono Sur, que se caracterizan por su carácter rural (como vimos en el Cuadro 2) y su depresión económica, se consolidan entre 2001 y 2012, como principales expulsoras de población, con índices de efectividad migratoria negativos. Los datos expuestos hablan de la dinámica poblacional de la que forman parte los trabajadores migrantes entrevistados; cuando uno conversa con ellos, ese es el sentido de sus afirmaciones : "mejorar económicamente", "para tener mejor calidad de vida"; "la decisión la tomaron mis papás, sobre todo, por mejorar económicamente, a esto se sumaba el clima y la comida" ; "mejorar nuestra situación económica con nuevas oportunidades laborales"; "aquí hay posibilidades de emprender un negocio, no hay tanta competencia como en La Paz, por ejemplo" (extractos de entrevistas a trabajadores migrantes) (Unidad de Análisis de Políticas Sociales y Económicas, 2018).

\subsection{Los orígenes migratorios de los obreros de la industria regional}

En el caso que estudiamos [?], la crisis de la economía parcelaria es la piedra de toque, para explicar que una importante proporción de estos obreros de la industria regional provenga del área rural y/o de padres que migraron del área rural, tanto del Departamento de Cochabamba como de otros departamentos. Aproximadamente, el 30 \% de obreros proviene del área rural de los departamentos de Potosí, La Paz, Oruro y Cochabamba (ver Gráfico 1). 
Gráfico 1 : Obreros Fabriles según área geográfica de nacimiento

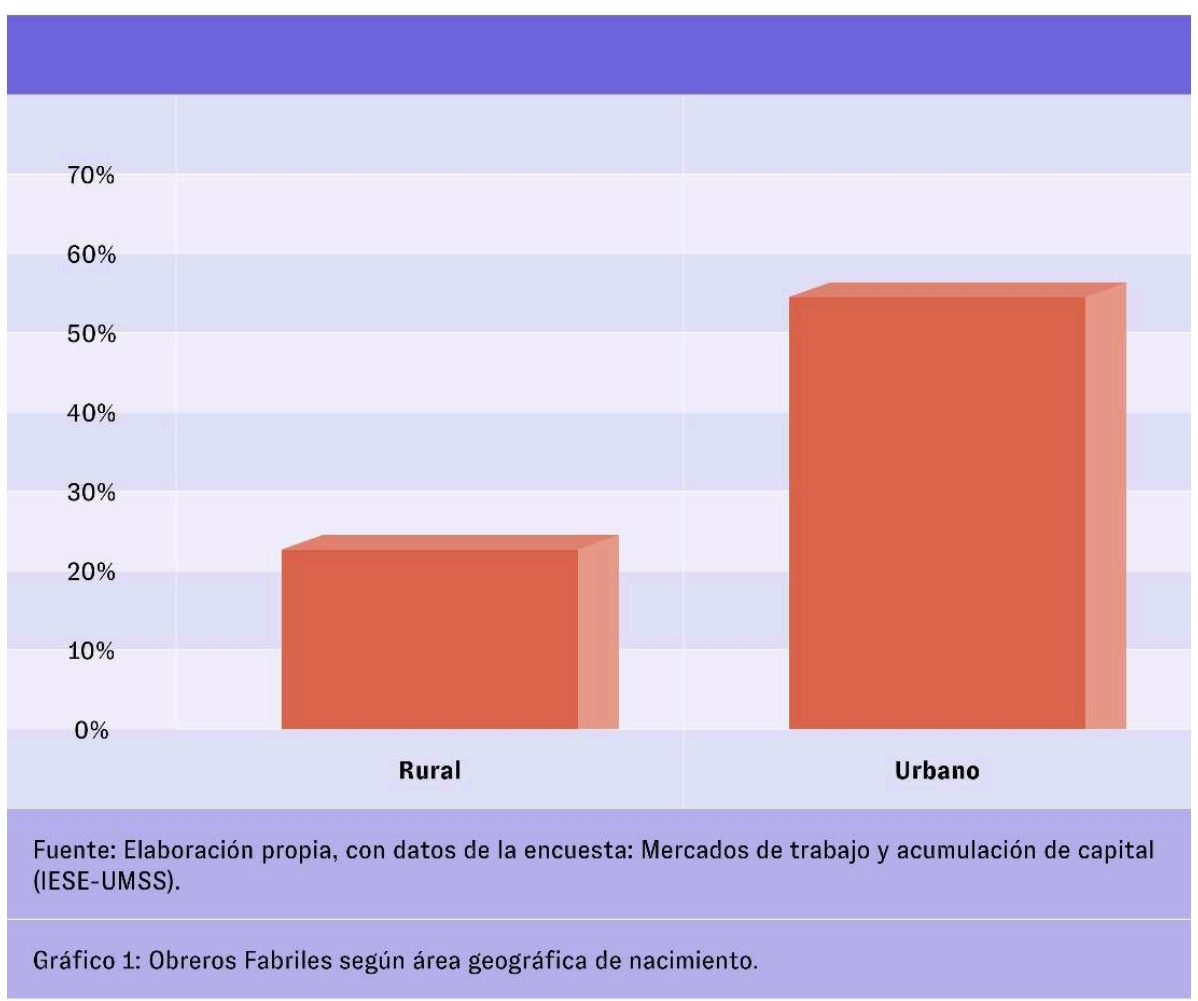

Gráfıco 1 : Obreros Fabriles según área geográfica de nacimiento

7 Los trabajadores dan testimonio de estos procesos migratorios forzados por los incipientes medios de subsistencia :

“(...) Muy bien, yo procedo de una familia que vive acá al lado de la FINO mismo, a unas dos o tres cuadras, en este sector siempre. Yo me crie con mis abuelos, que eran agricultores" (Extracto de entrevista a obrero de una empresa de aceite, 2014).

"Bueno, yo me llamo Zenón Cala, vengo de Potosí, mis padres son potosinos del campo, de allá del Norte de Potosí" (Extracto de entrevista a obrero de una empresa de bebidas, 2015).

“(...) Mis padres eran del campo, dedicaban a la agricultura, agricultores eran. En el campo no hay nada no, solamente es dedicarse a la agricultura. Cuando hay necesidad de platita íbamos, venían a Llallagua a Oruro a trabajarse, buscar economía no, solamente en el campo ahí para comer no más, eso así venían" (Extracto de entrevista a obrero de una empresa avícola, 2014).

Para estos obreros, el campo ya no era el lugar para labrar mejores condiciones de vida ; el campo está asociado a la escasez, a la falta de oportunidades, lo que explica y hace comprensible la decisión de migrar a las ciudades.

“(..) Allá ha sido mucha sequía, más que todo, la agricultura es para el consumo no más, a veces no alcanza, a veces, ahí tiempo no acompaña la lluvia, no acompaña los riegos, si no puro temporales digamos, con la lluvia no más, cuando no llueve no hay, no produce, no produce, falta para consumo (...), por eso hemos emigrado hacia Cochabamba, a Oruro a las ciudades hemos migrado, entonces, así he estado manteniendo, pero ya más 
sequía más sequía ha habido ; casi estoy como de 17 a 18 años" (Extracto de entrevista a un obrero de una empresa avícola, 2014).

9 La otra corriente importante, que alimenta la fuerza de trabajo fabril está formada por hijos de migrantes de poblaciones mineras nacidos en Cochabamba y otros que llegaron con sus padres, niños o jóvenes, como se interpreta de los testimonios obreros :

“(...) Bueno, primeramente, yo soy de Potosí de Tupiza. Nací en los centros mineros al Sud de Potosí. Bueno, mi papi es cochala, mi mami era de Tupiza. En realidad, su vida la realizaron allá cuando ellos se casaron, allá en Tupiza, en Quechisla...Trabajaba (su padre) en la empresa minera Quechisla, en la mina Quintisuyos, donde existen 14 secciones en la que se ubicaba la empresa minera Quechisla, eran distintos lugares o sea era como por decirte aquí Vinto, Quillacollo, allá se llamaba secciones y son 14 (...)" (Extracto de entrevista a obrera de una empresa de embutidos, 2015).

10 Aquí las decisiones individuales y/o familiares se entrelazan con procesos históricos de larga duración. La crisis de la economía parcelaria fue acelerada por medidas institucionales de corte neoliberal [8] que aumentaron el flujo de trabajadores del agro al área urbana, y por la llamada "relocalización", a mediados de los 80 del siglo pasado, que produjo el despido masivo de trabajadores de las minas estatales (como la mina Quechisla a la que se refiere nuestro entrevistado). Se trató de una diáspora de ex obreros de los centros mineros, que se dirigieron, unos, hacia la ciudad del El Alto en el altiplano, otros, se trasladaron hasta el trópico del departamento de Cochabamba, a una región conocida como el Chapare, mientras que otros se quedaron en la capital del departamento, la ciudad de Cochabamba [ ${ }^{9}$. Los que optaron por quedarse en la ciudad de Cochabamba, son los padres de niños y jóvenes que; posteriormente, pasarán a formar parte del contingente de obreros fabriles de la región.

11 Se observa que las trayectorias migratorias describen circuitos relacionados con los cambios en la orientación de la dinámica de acumulación del capital y con los cambios en la regulación de las relaciones sociales de producción, en este caso, con la flexibilización laboral y despidos masivos de trabajadores en la era neoliberal. Al interior de estos vastos procesos históricos, se tomaron decisiones personales y/o familiares, así es posible explicar, la importante proporción de obreros que encontramos con padres provenientes de las minas.

\section{Trayectorias laborales y configuración espacial de los mercados de trabajo}

12 En este apartado se descubre, cómo las trayectorias laborales, entendidas como un cambio entre diferentes actividades o tareas, que sintetizan procesos estructurales e historias personales y familiares, forman parte de las configuraciones espaciales que toman los mercados de trabajo de la industria en la metrópoli de Cochabamba. Para esto, identificamos en un primer momento, los espacios habitados por los trabajadores, en relación a su primera ocupación en la ciudad, para luego pasar a ver su movilización en el espacio, a medida que se consolida su proletarización ; es decir, su paso a formar parte del ejército activo de la industria regional. Luego se describe, cómo estos cambios en la ocupación del espacio, relacionados con la trayectoria laboral, confluyen en la 
forma espacial que asume, tanto la oferta como la demanda de trabajo en la región metropolitana de Cochabamba.

\subsection{Los espacios de expansión urbana como refugio de los trabajadores eventuales}

Desde la valoración de los obreros de la industria, la mejora de sus condiciones de vida está asociada a no vivir en el campo y dejar de ser campesino, por lo que la aspiración ascendente al llegar a la ciudad, implica la búsqueda de un cambio en su posición social; un proceso plagado de duras vivencias, atravesadas por las características de una industria regional pequeña, con serias dificultades para competir con productos del exterior, y que en gran medida provee a un mercado interno poco desarrollado, rasgo típico de una economía primario exportadora como la boliviana [ $\left.{ }^{10}\right]$.

La inserción laboral inestable que encuentran estos trabajadores en sus primeras ocupaciones, se capta en sus testimonios :

“(...) La mayoría de los trabajos ofertados son eventuales o por contratos de 3 meses, (...) en instituciones públicas se tiene que tener alguna muñeca [11]" (Extracto de testimonio de trabajador migrante en UDAPE, 2018, p. 71).

“(...) aquí encuentras trabajo de cosas básicas ; es decir, atender una tienda, mesera, donde te explotan y te pagan lo básico. Si quieres algo en una institución pública, por ejemplo, tienes que tener muñeca o charlado con alguien" (Testimonio de trabajadora migrante en UDAPE, 2018, p. 70).

“(...) Luego de peregrinar un poco en el tema de trabajo, porque empecé de pintor, hacía letreros luminosos en PANAFLEX, he estado unos seis meses en esa actividad" (Extracto de entrevista a obrero de una empresa de aceite, 2014).

“(...) Vendedor ambulante o los que ofrecen de otras empresas. Sí, ahí fui, el trabajo era muy pesado, porque esas veces estuvimos vendiendo licuadoras, ganábamos por porcentajes tenía que ir de Quillacollo a la ciudad, de la ciudad me llevaban al lado de Sacaba a ofrecer los productos, desde las 6 de la tarde teníamos que cambiar de oficina, informes, casi a las 8 llegaba a mi casa, con eso" (Extracto de entrevista a obrero de una empresa de bebidas, 2015).

La vivencia de estos obreros en su búsqueda de trabajo, muestra la dificultad de acceder a un puesto laboral al llegar a la ciudad, esto explicaría también, que se inserten a trabajos temporales, con bajos salarios, sin perspectivas a futuro: "Si, aquí en Cochabamba no es fácil, está saturado el mercado profesional, si quieres de tu profesión tienes que ir no más a Santa Cruz, alli hay hartas fábricas, industrias" (Extracto de entrevista a obrero industrial en UDAPE, 2018, p. 70). Entre ellos hay la percepción de que el mercado de trabajo ha sido colmado: "Ha venido mucha gente, han migrado y se ha saturado el mercado, por ejemplo, nosotros, nos hemos asociado y no hemos podido con este tema, conseguir trabajo fijo y formal, porque es más tema de charla, tener conocidos" (Extracto de entrevista a obrero industrial en UDAPE, 2018, p.71). Esta percepción de los mercados laborales saturados, se encuentra; principalmente, entre los jóvenes que consideran a sus padres como personas que tuvieron mejores oportunidades laborales al momento de migrar, porque accedieron a un empleo seguro o no tardaron mucho en conseguir un trabajo, ahora su incierta situación laboral ; posiblemente, los empujará a 
nuevas migraciones. El testimonio de estos trabajadores, saca a la luz, la angustia que vivenciaron por la inestabilidad laboral :

“(...) A veces no había trabajo, o a veces no nos pagaban, o sea yo digo la vida afuera los que no tienen seguro los que no están como nosotros como la empresas que tienen su seguro, o todo eso es muy triste, hoy mismo, veo eso los constructores, no, diría que son mal pagados, hoy en día están no más ganando bien pero no tiene esa clase de seguros de familia de trabajo mismo, no tiene esas cosas, yo lo he palpado ahí no, lo he palpado y he sufrido harto porque como te digo a veces no nos pagaban, nos pagaban cada fin de semana, no nos pagaban, nos decían a las 1 o 2 de la tarde les voy a pagar, el contratista se perdía esperabas 4, 5 de la tarde no había plata, no venía" (Extracto de entrevista a un obrero de una empresa de cerveza, 2014).

Se trata de una sobrepoblación que al refugiarse en espacios económicos de comercio y/o servicios, reproduce formas no capitalistas de subsistencia de tipo familiar, artesanal, etc., en unidades de producción que son parte de lo que otros autores denominan economía sumergida, "subterránea", "informal", son alternativas de ocupación precaria, frente al desempleo existente.

Una importante proporción de trabajadores, que tienen como primera ocupación trabajos precarios, las más de las veces por cuenta propia (chofer, mesera, ayudante de cocina, entretenimiento) o el de empleada doméstica, se asientan en zonas dispersas del espacio urbano. De nuestra muestra, un $50 \%$ de los trabajadores que vivían en zonas de expansión industrial y el $75 \%$ de trabajadores que vivían en asentamientos obreros, tenían como primer empleo, un empleo precario, por cuenta propia o eran empleadas domésticas (Gráfico 2).

\section{Gráfico 2 : Residencia según primera ocupación (en porcentaje)}

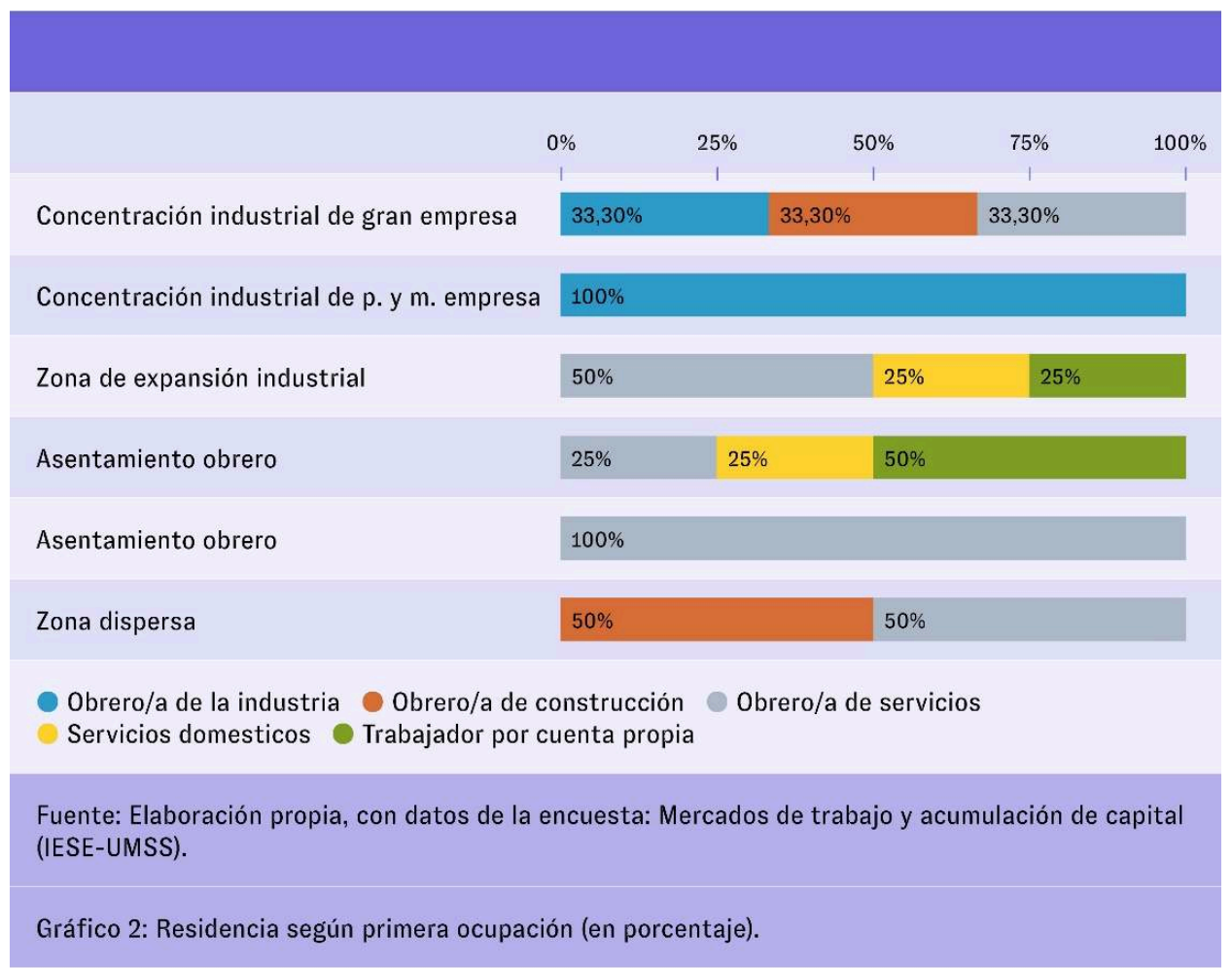

Gráfico 2 : Residencia según primera ocupación (en porcentaje) 
18 manufacturera, en la construcción o en servicios; entonces, los obreros se asientan en los espacios de concentración de la gran, mediana o pequeña empresa (Gráfico 2). Cabe notar, sin embargo, la importante presencia de obreros de la construcción y de servicios en zonas urbanas dispersas, una tendencia que puede explicarse, porque los sectores donde trabajan se caracterizan por contar con un amplio espectro de trabajadores subcontratados en condiciones laborales de precariedad, respecto de los trabajadores de planta.

Se ve que la trayectoria laboral de estos trabajadores, influye en su ocupación del espacio urbano; si el trabajo inicial ofrece una estabilidad relativa, como es el caso de ser obrero en una determinada empresa, se abre la posibilidad de desplazarse hacia las concentraciones industriales, respondiendo a la fuerza atractiva que tienen las empresas asentadas en estos espacios. Mientras las ocupaciones estén asociadas con la temporalidad, la subcontratación o los emprendimientos por cuenta propia, en condiciones precarias, los trabajadores tenderán a asentarse en las zonas de expansión industrial o expansión obrera; y en muchos casos, en espacios desdibujados, como las zonas dispersas, por el bajo costo de la vivienda o por su cercanía a coterráneos o familiares de una similar condición laboral. Es decir, a medida que la fisonomía de campesino o trabajador por cuenta propia, se va transformando en la de obrero, se producen desplazamientos en el espacio, a lugares que responden a su nueva ocupación y condición social, lugares establecidos alrededor de una identidad a lo largo de generaciones (Harvey, 1996/2018), como en el caso de los barrios obreros.

\subsection{Proletarización y ocupación del espacio}

Las aspiraciones de los trabajadores refugiados en actividades precarias, de llegar a ser trabajadores estables de la industria, se enfrentan a las limitaciones que impone un sector industrial pequeño, con una demanda relativamente baja de fuerza de trabajo. La carrera de estos trabajadores, encastrada en estos procesos sociales, que por largos períodos de tiempo, los condena a una frágil relación con los mercados de trabajo, está atravesada; también, por la redundancia y homogeneidad de las relaciones sociales (redes) formadas por familiares, amigos y vecinos, capaces de proveer empleos eventuales de forma continua, que, aunque son un refugio frente a la ausencia de mejores trabajos, pueden conducir al estancamiento en empleos precarios (Bayón, 2017). 
Gráfico 3 : Obreros de la industria manufacturera según motivos de cambio de un trabajo anterior al de la fábrica (en porcentaje)

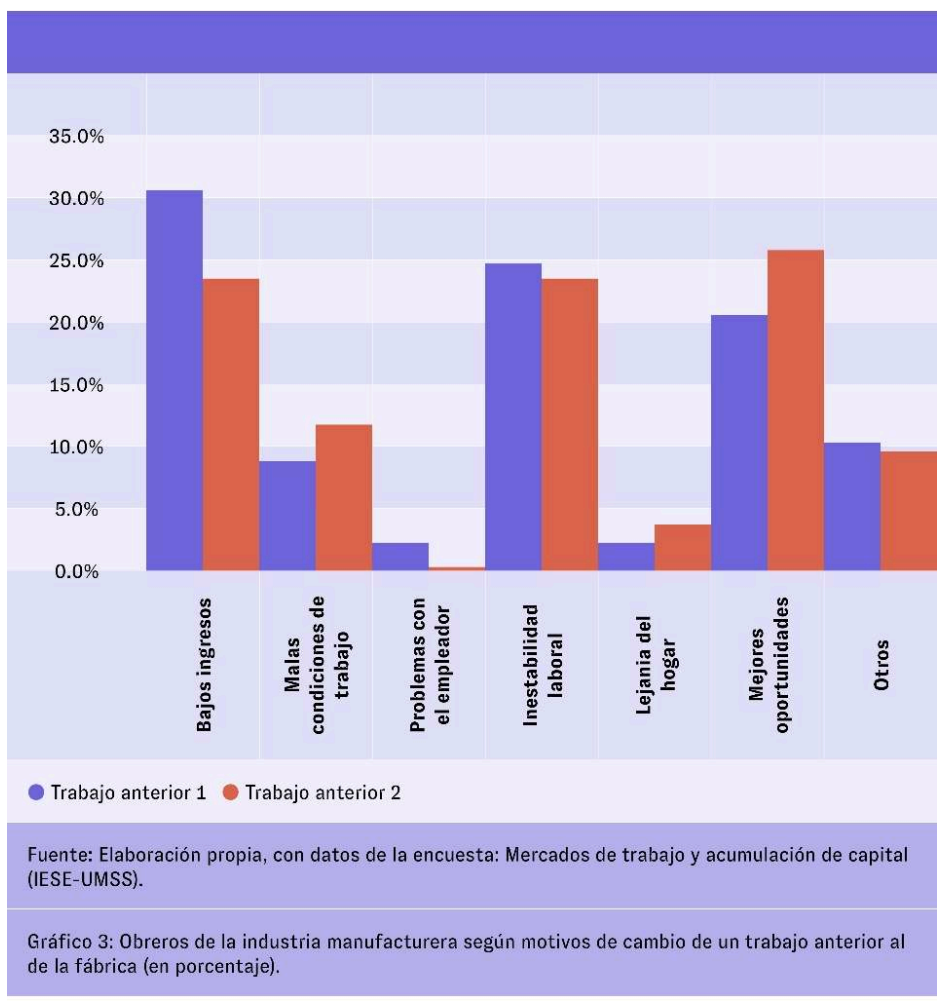

Gráfico 3 : Obreros de la industria manufacturera según motivos de cambio de un trabajo anterior al de la fábrica (en porcentaje)

21 En estas circunstancias, para estos obreros, alcanzar a formar parte de la plantilla laboral de una fábrica, significa un ascenso económico y social muy importante. La fábrica entre los trabajadores entrevistados está asociada a estabilidad laboral, a la apertura de mejores oportunidades de trabajo y a la posibilidad de tener mejores ingresos (Gráfico 3). Las vivencias de los obreros y obreras de la industria nos hablan de sus sueños, su insistencia y su perseverancia, para ser admitidos en un puesto de trabajo en la industria :

"Luego he insistido bastante en FINO, porque me he enfocado ahí, más de cerca que los trabajadores, para mí era un orgullo bien uniformados, de blanquito, yo no conocía nada de eso y eso me ha llamado bastante la atención y he querido de alguna forma entrar, pertenecer, y he insistido, como portero, pero a veces, bloquean mucha la situación, tal vez porque ellos quieren que avalar al jefe, y se han considerado que ellos asuman una vacancia en planta por decir y restringen a los demás" (Extracto de entrevista a obrero de una empresa de aceite, 2014).

La representación que tiene este obrero, de pertenecer a una industria como la de aceites FINO, está asociada a acceder a algo mejor, algo desconocido, algo que le haría sentir orgulloso. En otros obreros, el ingreso a una fábrica fue el resultado de perseguir un anhelo :

"En realidad, todo esto era un anhelo de mí, desde pequeño cuando veía la empresa, quería trabajar en esta empresa. Bueno siempre he soñado con entrar ¿no? Se ha cumplido mi sueño de poder pertenecer a esta gran 
empresa. Entonces, es en ese sentido que estoy hasta estos días, trabajando ¿no ?" (Extracto de entrevista a obrero de una empresa de lácteos, 2014). el campo, hacerse a la vida urbana, en términos no sólo económicos; sino también culturales, abrir perspectivas de ascenso social para los hijos; ofrecerles mejores oportunidades de estudio y de trabajo, en una situación en la que el campo significa aislamiento, pobreza y atraso, una valoración que permea la percepción obrera, acerca de su acceso a un puesto de trabajo fabril :

“(...) Y ese tiempo lo he valorado harto, cuando gracias a Dios me reciben en la institución, y en ese trayecto de ida y venida, siempre iba insistiendo en las mañanas como es, si había una vacancia en PIL, en FINO, en UNILEVER, en COCA COLA, a diferentes lugares que había postulado tal vez y suerte" (Extracto de entrevista a obrero de una empresa de aceites, 2014).

Muchos de estos trabajadores no accedieron a su primer empleo en la industria, como obreros de planta, sino a través de una empresa subcontratista, en calidad de obreros fluctuantes (Castro, 2016) ; esto no importaba, el hecho era ingresar al sector, para luego tener la oportunidad de convertirse en obrero de planta :

“(...) Con una tercerizadora entré, justamente ahí he trabajado. Me hicieron la entrevista con este jefe, el mismo de ingeniería industrial, era el jefe de esa empresa tercerizadora, ahorita recién ya puedo identificar algunas normas, pero de cierta forma, ésa ha sido mi puerta para poder ingresar a la planta. Luego he trabajado como ocho meses de limpieza, en la cual vi canalizando, viendo como buscar lugar dentro de planta, ese tiempo, aproximadamente, de ocho meses con la empresa tercerizada me animé a hablar con los jefes de área, he conocido a todos los ingenieros de área y empecé a socializar, de hablar, charlar y he pedido también su apoyo de ellos, y bueno uno con buen carácter me ha aceptado" (Extracto de entrevista a obrero de una empresa de alimentos, 2015).

El ingreso a la fábrica, significa el primer paso para iniciar un proceso de ascenso social, desde un perfil campesino o de trabajador por cuenta propia, que habita en los intersticios de la economía regional y en las zonas agrarias o de expansión urbana, a convertirse en integrante del ejército activo de trabajadores de la industria. Pero este proceso, como cualquier otro, no es neutro, debido a que la división de clases, la opresión de sexos y de etnias, impone que cada individuo desarrolle sus capacidades de forma unilateral, pudiendo extender unas y atrofiar otras ; esto saca a la luz, los límites que encuentran los individuos, para hacer de las riquezas de la cultura su propiedad, porque estos límites no dependen solo de ellos, sino de los rasgos de la sociedad en que están inmersos (Ilyénkov, 1982/2007). En este sentido, el curso que la carrera de los obreros de la industria regional dibuja, está permeado por las desigualdades de clase y la opresión social de sexo y de etnia.

Una primera aproximación muestra que el nivel de instrucción de estos trabajadores (que incide en sus posibilidades de carrera) está relacionado con la ocupación del padre (como proxy del origen de clase). Los obreros que tienen como padre a un campesino agricultor, en mayor proporción, sólo alcanzan el nivel primario de instrucción, una notoria menor proporción estudian hasta nivel secundario, mientras es menos frecuente encontrarlos con una formación a nivel técnico o universitario (Gráfico 4). El ser hijo de un obrero minero parece abrir más posibilidades de formación, un $40 \%$ de

Laboreal, Volume 17 №2 | 2021 
entre ellos, se distribuye entre los niveles de formación de técnico medio, superior y licenciatura. Sin embargo, la mayor oportunidad de formarse a nivel de técnico medio, técnico superior o nivel universitario, está asociada a tener padres que realizan o realizaron actividades en el espacio urbano; resalta que los hijos de oficinistas (que pueden asimilarse a una clase media urbana) distribuyan su formación entre técnica superior y universitaria en aproximadamente $55 \%$, (Gráfico 4) [12].

Gráfico 4 : Nível de instrucción del obrero/a de la industria manufacturera según ocupación del padre (en porcentaje)

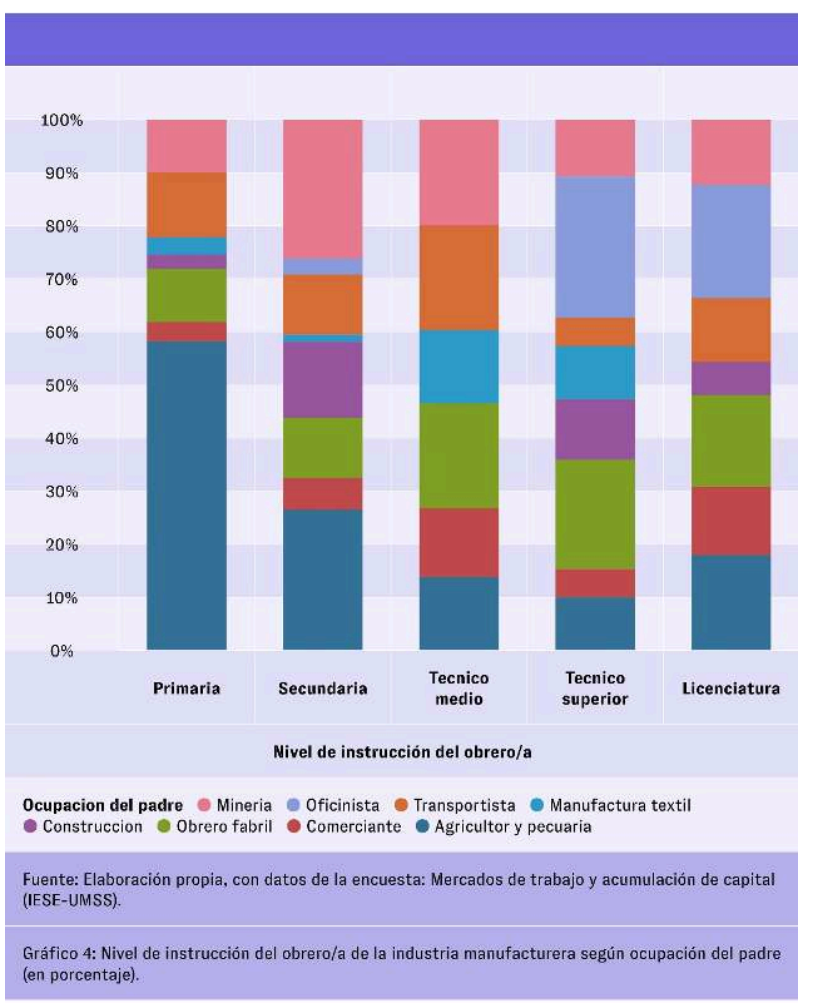

Gráfico 4 : Nível de instrucción del obrero/a de la industria manufacturera según ocupación del padre (en porcentaje)

El origen de clase, que incide en los alcances del nivel de formación de estos obreros, influye, además, en el curso de su trayectoria ocupacional dentro de la división técnica del trabajo. El transporte y la logística (asociada a tareas de limpieza) concentra a la mayor proporción de hijos de agricultores, mientras que su presencia es mínima en ocupaciones como técnicos de mantenimiento o inexistente en puestos de control como el de supervisor o capataz, a comparación de los hijos de oficinistas (clase media urbana), que, en importante proporción, ocupan puestos de control como los de capataz o supervisor (Gráfico 5). Cabe resaltar que el tener como progenitor a un obrero, sea este minero o fabril, facilita que los hijos accedan a puestos de cierta jerarquía obrera en la fábrica, como los de capataz o supervisor o como los de técnico de mantenimiento. Si se observa la información del Gráfico 5, una gran proporción de los obreros que ocupan estos puestos son hijos de mineros o de obreros fabriles de la manufactura textil o de obreros del sector de la construcción. De ahí que la transición del padre, desde la condición de campesino hacia la de obrero, constituye como ellos lo perciben, un puente para mejorar la posición dentro de la escala jerárquica de puestos 
que brinda la empresa. Es decir que, de alguna manera, la posición del padre, dentro de la división social del trabajo, incide en la trayectoria ocupacional de estos trabajadores.

Gráfico 5 : Puesto de trabajo del obrero/a de la industria manufacturera según ocupación del padre (en porcentaje)

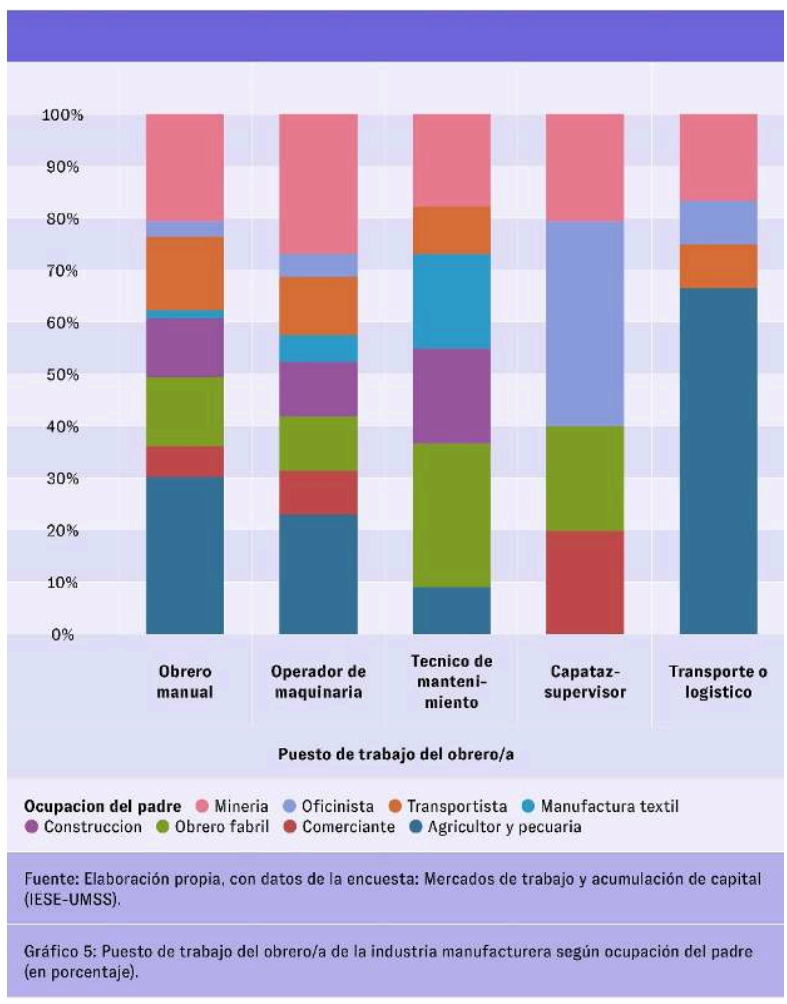

Gráfico 5 : Puesto de trabajo del obrero/a de la industria manufacturera según ocupación del padre (en porcentaje)

Ser mujer trabajadora en la industria, delinea también, las sendas de la trayectoria ocupacional dentro la división técnica del trabajo. Es notoria la segregación que concentra a las mujeres en ciertas ocupaciones. Si al inicio de su carrera laboral en la ciudad, las encontramos concentradas como trabajadoras domésticas, auxiliares de restaurantes o en el pequeño comercio por cuenta propia, en las fábricas tienen la exclusividad de las tareas de limpieza o se concentran en otras ocupaciones que demandan destrezas manuales (control de calidad, operador directo o manual); no se encuentra obreras en ocupaciones relacionadas con una formación técnica, como las de operador de instalaciones o de mantenimiento, de técnico de campo o de controlador de procesos. Si se asocia esta segregación en la ocupación, con las posibilidades de ascenso laboral, vemos que las ocupaciones de limpieza o la de obrero manual, donde se concentran las trabajadoras, son las que tienen menos posibilidades de este ascenso (Gráfico 6). En las mismas estadísticas se aprecia, cómo el origen rural de un obrero u obrera, limita sus posibilidades de ascenso en la escala ocupacional de la empresa. 
Gráfico 6 : Obreras y obreros de la industria Manufacturera de Cochabamba según ascenso laboral por sexo y área de origen

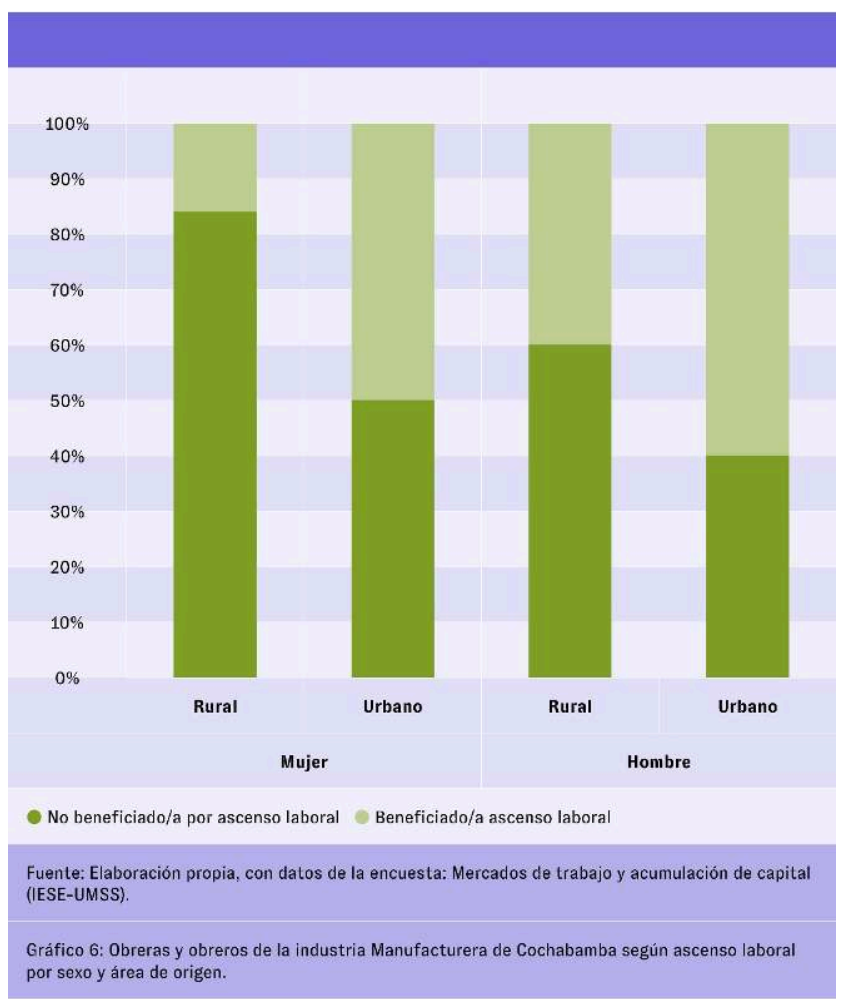

Gráfico 6 : Obreras y obreros de la industria Manufacturera de Cochabamba según ascenso laboral por sexo y área de origen

En consecuencia, estas trayectorias en la división técnica del trabajo, según el sexo y el origen étnico, muestran las desiguales oportunidades que tienen estos obreros, para forjarse una carrera que contribuya a que salgan de los espacios urbanos difusos y se ubiquen en los lugares que acogen al contingente consolidado de obreros de la industria, como se ve a continuación. 
Gráfico 7 : Obreros de la industria por ocupación, según espacio de residencia (en porcentaje)

\begin{tabular}{|c|c|c|c|}
\hline \multirow[b]{2}{*}{ Concentración industrial de gran empresa } & $25 \%$ & $50 \%$ & $100 \%$ \\
\hline & $45,6 \%$ & $52,1 \%$ & $2 \%$ \\
\hline Concentración industrial de p. y m. empresa & $65,6 \%$ & $23,8 \%$ & $7,4 \% 3 \%$ \\
\hline Barrios Obreros & $51,5 \%$ & $40,1 \%$ & $8,6 \%$ \\
\hline Zona de expansión industrial & $61,9 \%$ & $28,0 \%$ & $7,3 \% 3 \%$ \\
\hline Asentamiento obrero & $54,1 \%$ & $40,0 \%$ & $4 \% 2 \%$ \\
\hline \multicolumn{4}{|c|}{$\begin{array}{l}\text { Obrero/a manual Operador/a de maquinaria Tecnico de mantenimiento } \\
\text { Capataz/supervisor }\end{array}$} \\
\hline \multicolumn{4}{|c|}{$\begin{array}{l}\text { Fuente: Elaboración propia, con datos de la encuesta: Mercados de trabajo y acumulación de capital } \\
\text { (IESE-UMSS). }\end{array}$} \\
\hline
\end{tabular}

Gráfico 7 : Obreros de la industria por ocupación, según espacio de residencia (en porcentaje)

30 Si se hace una aproximación más fina, y se relaciona la trayectoria de estos obreros, dentro de la división técnica del trabajo, con el espacio en el que residen, en el Gráfico 7 sobresale la importante presencia de obreros operadores de maquinaria (con mayor formación técnica que los obreros manuales), en espacios de concentración de la gran industria, mientras que su presencia es mucho menor en zonas de expansión industrial $(28,0 \%)$, donde sobresale la presencia de obreros manuales, los que también se concentran de manera mayoritaria en asentamientos obreros y barrios obreros, en $51,5 \%$ y $54,1 \%$ respectivamente; aunque la presencia minoritaria de los obreros operadores de maquinaria, en estos espacios, es también importante.

31 Cabe resaltar, por una parte, que los obreros manuales se ubican en proporción mayor, en las concentraciones industriales de mediana y pequeñas empresas, esto en razón a que son este tipo de empresas, las que demandan una fuerza de trabajo con habilidades manuales, por lo que se convierten en polo de atracción, para este tipo de trabajadores ; por otra parte, la menor presencia relativa en estos espacios, de obreros que han pasado a la categoría de técnicos de mantenimiento o de capataces (Gráfico 7), cuyo perfil profesional se aleja del perfil obrero y se va aproximando al de los ingenieros o managers de proximidad, se explica justamente, porque tienen la posibilidad de dejar esta constelación del espacio urbano asociado a la condición de trabajador precario o de obrero, para ocupar barrios de trabajadores de clase media.

La tendencia observada nos indica que a medida que el perfil obrero se consolida, con el paso de ocupaciones que demandan trabajos manuales (con menor estabilidad laboral, por ser fácilmente sustituibles), a otras que exigen mayores destrezas técnicas y experiencia ; los obreros ven la alternativa de adquirir una casa propia en los barrios obreros consolidados o en las concentraciones industriales [13] (65\% de nuestros encuestados ocupaba una casa junta como vivienda), donde el precio del suelo urbano 
es más alto, en relación al precio que se encuentra en las zonas dispersas, de asentamiento industrial $\mathrm{u}$ obrero. Sin embargo, este anhelado camino a la proletarización (que incide en una forma de ocupación del espacio urbano) ; como no podía ser de otra manera, se da dentro de un proceso de segregación residencial, que actúa como mecanismo de reproducción de desigualdades socioeconómicas, de las que ella misma es una manifestación (Segura, 2006). Se trata de una segregación urbana que se muestra en las características de los barrios que habitan; zonas de la periferia urbana, en las que persisten en importante proporción (pese a la gran expansión del pavimento asfáltico en el perímetro metropolitano de Cochabamba), las calles de tierra, de piedra o con ripio; un indicador de que muchos de estos espacios no pasaron por un saneamiento urbano. Se ve que la constitución del espacio no se puede divorciar de las relaciones sociales, porque la designación de un lugar dentro de la estructura socio espacial indica roles específicos, capacidades de acción y acceso al poder (Harvey, 1996/2018).

\subsection{Los mercados de trabajo de la industria en el espacio metropolitano}

33 La dinámica sociológica que termina por consolidar a trabajadores migrantes, como obreros y obreras de la industria regional, tiende a concentrarlos, espacialmente, alrededor de unidades productivas que devienen en espacios laborales relativamente estables. Con fines analíticos; distinguimos los espacios que forman parte de la configuración de los mercados de trabajo, de acuerdo a los diversos grados de concentración de empresas y trabajadores de la industria manufacturera, en la región metropolitana de Cochabamba.

Resalta en el mapa 1, en color rojo, una concentración espacial de industrias, que en relación al tamaño de la economía boliviana, pueden ser consideradas como grandes empresas (sociedades anónimas, algunas con capitales transnacionales). Es una concentración industrial, cuyo origen data de mediados de la década de los 50 del siglo pasado, un origen asociado a la política de diversificación productiva que trató de impulsar en la región, el Gobierno del Movimiento Nacionalista Revolucionario (MNR), luego de la revolución nacional de 1952 [14]. Se trata de una concentración industrial ubicada cerca de la carretera que une a la ciudad de Cochabamba, con centros urbanos secundarios como Colcapirhua y Quillacollo, y que une el occidente y oriente del país, una ubicación que puede estar relacionada en términos estratégicos, con la reducción de costos de transporte, tanto de las materias primas, como de los productos que salen, para destinarse a los mercados nacionales e internacionales; un modelo de asentamiento orientado a la oferta, que enfatiza la localización industrial en función del proceso productivo, para minimizar los costos de producción (costo mínimo de producción), mediante la conjugación del costo de adquisición de insumos y del costo de distribución del producto (Weber, 1929). 
Mapa 1 : Ubicación de unidades industriales y lugar de residencia de trabajadores del sector industrial en el área metropolitana Cochabamba, según zonas de concentración
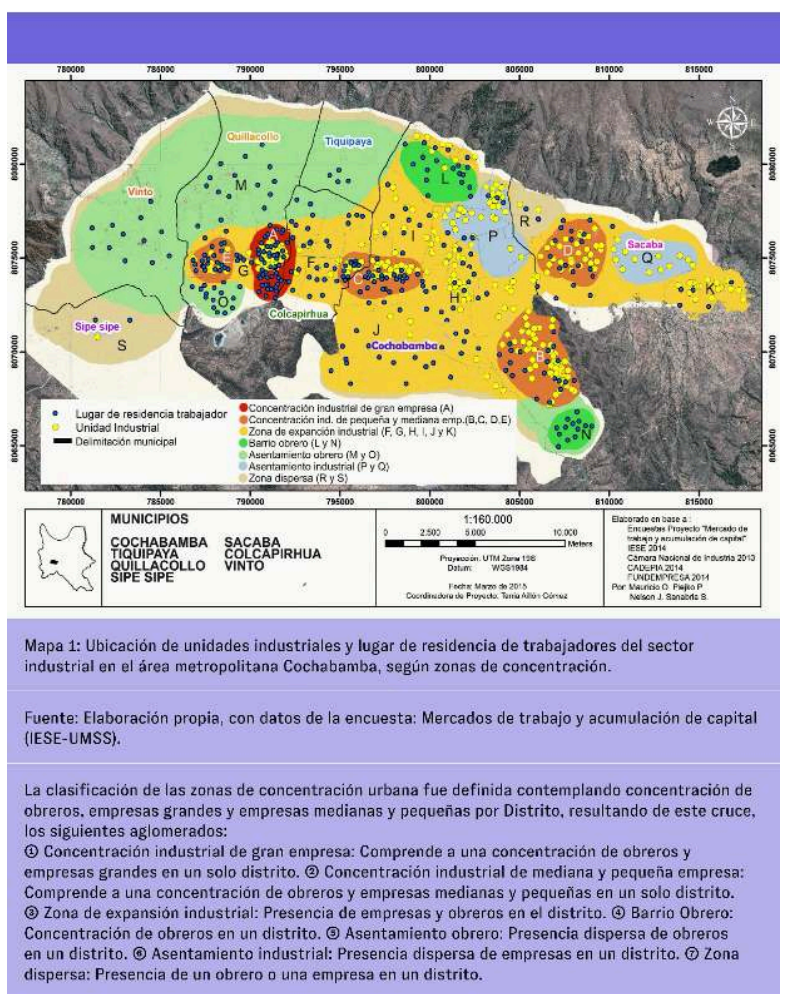

Mapa 1 : Ubicación de unidades industriales y lugar de residencia de trabajadores del sector industrial en el área metropolitana Cochabamba, según zonas de concentración

En color salmón se distinguen hasta 4 concentraciones de industrias medianas y pequeñas, de gran importancia regional, en términos de generación del empleo. La primera (resaltada con la letra B) de estas concentraciones, se encuentra en el Sudeste de la ciudad, conocida como Villa Pagador (ver Mapa 1); habitada por migrantes del departamento de Oruro, es una concentración de pequeños talleres y empresas medianas, con especialización en la costura de prendas de vestir, que desde los años 60 del siglo pasado, recibió oleadas de migrantes formados en sastrería y costura, que fueron formando talleres, aprovechando la mano de obra que continuaba llegando desde el departamento de Oruro. En este caso, se puede decir que la localización de las empresas pequeñas y medianas, se consolidó por el acceso a una mano de obra barata y cualificada. La segunda concentración (resaltada con letra C en el mapa1), se ubica en barrios que se extienden, entre la ciudad de Cochabamba y la carretera que pasa a Colcapirhua y Quillacollo (centro urbano secundario) en dirección a la concentración de grandes y medianas empresas; se trata de empresas dedicadas a la producción de artículos de cuero, confección y de producción de bebidas. La tercera concentración (resaltada con la letra D, en el mapa1) con estas características, se ha localizado en la conurbación entre el centro metropolitano y el centro urbano secundario de Sacaba, sobre la carretera que une el departamento de Cochabamba con el oriente del país. Finalmente, la cuarta concentración industrial (resaltada con la letra E en el mapa 1) se ubica entre Quillacollo (centro urbano secundario) y un centro poblado cercano, Vinto. Ella forma parte del proceso histórico de concentración de grandes empresas, al que nos referimos al inicio de este acápite. 

2 poblaciones obreras concentradas, la primera (letra L) situada al Norte de la ciudad de Cochabamba ; se trata de barrios obreros planificados (barrio Taquiña, barrio Vidriolux, etc.), por acuerdos entre las empresas y los sindicatos de trabajadores. La segunda concentración de barrios obreros (letra N) está situada en la antigua carretera que une a Cochabamba con el oriente del país, en antiguos asentamientos de migrantes del área rural (La Tamborada, y Santa Vera Cruz, Uspha Uspha). Como pudimos ver, estos barrios obreros forman parte importante de la reproducción de esta formación espacial de los mercados de trabajo y son el resultado del desplazamiento de aquellos obreros y obreras, que, debido a sus trayectorias laborales, terminan consolidando su posición como obreros de la industria manufacturera regional. circundan, tanto a la concentración de las grandes empresas, como a las concentraciones formadas por la pequeña y mediana industria. Estas zonas se caracterizan por tener una concentración moderada de obreros y empresas, lo que sugiere que son lugares hacia los que tienden a expandirse las industrias, una suerte de primer anillo de expansión industrial. La primera zona de expansión industrial, va de Este a Oeste; alrededor de la carretera que une la ciudad de Cochabamba con Quillacollo; hacia el Oeste la zona de expansión industrial, se une con el centro industrial formado por la gran industria y con los centros industriales de la pequeña y mediana industria, ubicados hacia Quillacollo. Hacia el Este de la ciudad de Cochabamba, la zona de expansión industrial, se une tanto con el centro industrial donde se ubican las grandes industrias, como con el centro industrial de pequeñas y medianas empresas de la ciudad de Cochabamba.

En verde claro (M), se observan los asentamientos obreros que bordean, tanto las concentraciones industriales como las áreas de expansión industrial (parte norte del centro urbano secundario como Quillacollo, Tiquipaya y Vinto), son asentamientos dispersos, donde no se localizan empresas industriales. Finalmente, se observa 2 zonas de expansión industrial en color celeste ( $\mathrm{P}, \mathrm{Q})$, donde existen empresas asentadas de forma dispersa ; una de estas zonas está en el norte de la ciudad de Cochabamba y la otra, en una zona situada entre el área de concentración de la pequeña y mediana empresa y Sacaba ; son los espacios que no definen todavía un perfil industrial u obrero. En este caso, su carácter espacialmente difuso, está asociado a la composición social variopinta de sus habitantes: artesanos dedicados a actividades por cuenta propia; pequeños comerciantes ambulantes, albañiles con trabajos temporales $u$ obreros fluctuantes en las industrias manufactureras o de la construcción ; componentes de esa amplia sobrepoblación relativa, propia de formaciones sociales como la boliviana.

\section{Consideraciones finales}

39 Al inicio, nos propusimos comprender y explicar a los mercados de trabajo de la industria, como espacios producidos socialmente, introduciendo a las trayectorias laborales de obreros y obreras, como el hilo conductor que entrelaza las decisiones individuales o familiares con procesos sociales generales más vastos. El material empírico nos llevó a identificar que las trayectorias laborales incrustadas en la disolución permanente de las formas parcelarias de producción y en la dinámica de la industria regional, de un país primario exportador, implicaban cambios en las 
relaciones sociales que estos trabajadores entablan para reproducir sus medios de vida. Cambios que marcan su tránsito de campesinos parcelarios y trabajadores por cuenta propia (formas no capitalistas de producción) a obreros de la industria (relaciones sociales capitalistas de producción).

Este proceso de proletarización, que como muestra la referencia empírica, se asocia a un desplazamiento o reubicación de los obreros en las concentraciones industriales, como espacios de atracción de fuerza de trabajo, o en los barrios obreros, es una ilustración de que los espacios que configuran los mercados de trabajo de la industria manufacturera sólo pueden comprenderse como resultado de una metamorfosis social, que conjuga las condiciones de posibilidad de esta proletarización, con las aspiraciones de trabajadores eventuales o por cuenta propia, de llegar a convertirse en trabajadores estables de la industria regional. Pero como se pudo apreciar, esta conversión no es lineal, depende de un entramado social que conjuga la clase de origen, el sexo, el origen rural o urbano ; un entramado que facilitará o dificultará las aspiraciones de ascenso social que mueve a estos trabajadores, que ven en la fábrica una puerta a mejores condiciones de vida y de trabajo, relacionadas, directamente, con la posibilidad de establecer su vivienda en espacios más cercanos a sus centros de trabajo, lo que implica reproducir un orden social que toma forma en el espacio urbano, segregándolos a "sus lugares", que aunque sean deficientes en equipamiento urbano $u$ ornato público, son generalmente valorados como mejores que los que se dejan atrás en el espacio rural, o en las zonas de expansión urbana, con asentamientos dispersos y con carencias mayores, que las que tienen en los lugares a los que pueden acceder en calidad de obreros de la industria.

41 Estas aspiraciones en sus posibilidades de ascenso social, como observamos, difieren de acuerdo al origen de clase, al origen regional o al género de los trabajadores, debido a las desigualdades de acceso a la formación profesional o a las desigualdades que brindan las empresas en las posibilidades de ascenso laboral, en la medida en que éstas constituyen también, espacios de reproducción de los valores patriarcales o de segregación étnica, que dificultan el ascenso laboral a los grupos de trabajadores de sexo femenino o de origen rural.

Los cambios de clase social muestran que una proporción importante de estos obreros de la industria, transitaron de campesinos agricultores a obreros; en este caso, el cambio en términos de clase social significa un cambio cualitativo importante, sobre todo, en relación al reconocimiento social, que los propios obreros dan a la transición de campesinos a obreros, algo que explicaría, como pudimos apreciar en sus testimonios, su persistencia por convertirse en parte del proletariado fabril. Otra parte de obreros, mantuvo la posición de clase del padre, que formó parte de la clase obrera minera o manufacturera. No se observa, en consecuencia, una importante movilidad social de estos obreros, en relación a la generación de sus padres; las razones tienen que ver con las estrechas posibilidades de movilidad socioeconómica que encuentran éstos, como migrantes de primera generación, al arribar a las ciudades, lo que incide en las oportunidades de formación profesional, que pueden ofrecer a los hijos o en el poco "capital social" con el que cuentan, para acceder a oportunidades de trabajo.

Como se pudo observar, sin considerar las zonas de expansión urbana en que se asienta gran parte la sobrepoblación relativa, tampoco es posible comprender la dinámica socioeconómica de los mercados de trabajo de la industria regional. Se trata en términos espaciales, de la población que produce y habita los contornos de los núcleos 
formados por las concentraciones industriales y los barrios obreros ; más precisamente, sus zonas de expansión, como si esta población estuviera a la espera de incorporarse al ejército de obreros activos de la industria regional, para desplazarse a las cercanías de las fábricas o formar parte de los barrios obreros.

Nuestro enfoque parece ser fértil, para comprender y explicar, cómo las trayectorias laborales son parte de procesos y de tendencias estructurales a largo plazo, al mismo tiempo que son el resultado de prácticas, estrategias y representaciones que desarrollan los obreros y obreras a lo largo de su vida laboral; una dinámica dentro de la cual, la dimensión espacial no sólo es el marco donde actúan y participan los trabajadores, sino que es también, el resultado de las trasformaciones en las relaciones sociales, bajo las cuales, ellos reproducen sus medios de existencia ; esto saca a la 1 luz, las grandes posibilidades heurísticas del espacio, en el estudio del trabajo.

\section{BIBLIOGRAFÍA}

Bartra, A. (1982). La explotación del trabajo campesino por el capital. México : Editorial Macehual.

Bayón, C. (2017). Ciudadanías periféricas. Desigualdad, pobreza y fragmentación de los márgenes urbanos. In P. Ramírez (Coord.), La erosión del espacio público en la ciudad neoliberal.

(pp. 263-293). México : Universidad Nacional Autónoma de México. Instituto de Investigaciones Sociales-Facultad de Arquitectura.

CEDLA (2017). Analizando los resultados del Censo Agropecuario 2013. La Paz. https://cedla.org/ publicaciones/prya/explotaciones-agropecuarias-a-cargo-de-hombres-y-de-mujeres-y-tenenciade-la-tierra/

Castro, L. (2016). Obreros fluctuantes frente a la dominación patronal. El caso de la Refinería Gualberto Villarroel en Bolivia. La Paz : Muela del Diablo Editores.

Centro de Estudios de Población - Universidad Mayor de San Simón (2018). Características Demográficas básicas del Departamento de Cochabamba (mimeógrafo).

Grebe, H. (2017). Los ciclos de la economía mundial y el desarrollo de Bolivia. In I. Velázquez, \& N. Pacheco (Coords.), Un siglo de economía en Bolivia (1900-2015). Tópicos de historia económica (pp. 49-96). La Paz : Fundación Konrad Adenauer.

Grupo LLank'aymanta (2008, octubre - noviembre). Lucha de clases en Bolivia : Contenido y tendencias del proceso político actual. Jornadas Internacionales de Investigación y Debate Político (VII J ornadas de Investigación Histórico Social) "Proletarios del mundo, CEICS, Buenos Aires, Argentina.

Harvey, D. (2018). Justicia, naturaleza y la geografía de la diferencia. Quito : Instituto de Altos Estudios Nacionales del Ecuador.

Ilyénkov, É. (2007). Dialéctica de lo abstracto y lo concreto en "El Capital” de Marx. Quito : Ediciones Edithor.

Kosik, K. (1990). La dialéctica de lo concreto. México D. F. : Barsa. 
Marx, K. (1985). El capital, Tomo I. Mexico D. F. : Siglo XXI.

Pattaroni, L. (2016). La trame sociologique de l'espace. Sociologies. https://doi.org/10.4000/ sociologies.5435

Segura, R. (2006). Segregación residencial, fronteras urbanas y movilidad territorial. Un acercamiento etnográfico. Cuadernos del IDES, 9, 1-25.

Tripier, P. (1998). De la Théologie protestante a la sociologie du travail. Archéologie des travaux de Hughes et la Seconde Ecole de Chicago. Travail et Emploie, 75, 33-48.

Urioste, M. (2003). La reforma agraria abandonada : Valles y altiplano. In J. Vargas (Coord.), Proceso agrario en Bolivia y América Latina (pp. 19-52). La Paz : Plural.

Unidad de Análisis de Políticas Sociales y Económicas - UDAPE (2018). Migración interna en Bolivia. La Paz: UDAPE.

Weber, A. (1929). Theory of the location of industries. Chicago: University of Chicago Press.

\section{NOTAS}

1. Cochabamba forma parte del eje metropolitano de Bolivia, junto con La Paz y Santa Cruz.

2. Dado que no es posible visibilizar con información oficial el universo de obreros y obreras que existen por ramo en el área metropolitana de Cochabamba, se elaboró un indicador poblacional aproximado $\left(\mathrm{N}^{\mathrm{N}}\right)$, a través de una ponderación proporcional llevada a cabo con el ratio entre el número de empresas de los ramos industriales a estudiar y el número total de empresas de la industria manufacturera en Cochabamba según clasificación (CIIU) de FUNDEMPRESA para el año 2014. El producto de esta ponderación proporcional con el número de obreros/empleados que trabajan en la industria manufacturera registrados en el Censo de Población y Vivienda 2012, representa el universo estimado por ramo industrial.

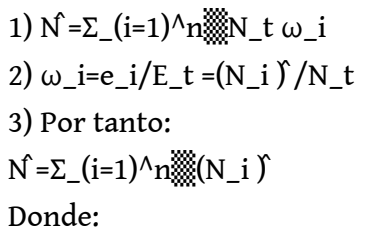

N_t: Corresponde al número total de obreros de la industria en los municipios de Cercado, Quillacollo, Sacaba, Colcapirhua y Tiquipaya según datos del Censo de Población y Vivienda (2012).

$\mathrm{N}^{\wedge}$ : Corresponde al universo total estimado de los ramos de alimentos, bebidas, textiles y curtiembres.

$\hat{N} \_$i: Corresponde al universo total estimado del ramo i.

$\omega_{-} i: P e s o$ ponderado del rubro i.

e_i:Corresponde al numero total de empresas del ramo i,segun datos de FUNDEMPRESA

Et: Corresponde al número total de empresas, según datos de FUNDEMPRESA

3. Este tipo de muestreo consiste en distribuir el tamaño de la muestra total en función del tamaño sub poblacional (rubro industrial) de modo que las sub poblacionales más grandes tengan una sub muestra proporcionalmente mayor: Donde:

: Muestra del estudio

: Sub muestra del rubro i

: muestra del estudio

: Total de empresas

Por su parte, para la determinación del tamaño de la muestra se manejó la formula muestral para 
variables de tipo atributo y población finita:

Donde:

$\mathrm{n}$ : Tamaño de la muestra

$\mathrm{N}$ : Número de obreros del rubro especifico

$\mathrm{Z}$ : Valor de distribución normal $\mathrm{Z}$ a un nivel de confianza del $95 \%$

p: Probabilidad de ocurrencia del evento

q: Probabilidad de no ocurrencia del evento

Em: Error estándar de estimación

Se estableció un nivel de confianza del $95 \%$ que en términos de valores estandarizados Z corresponde a 1,96. Asimismo, se asume que la muestra tendrá un error del 4,6\% (Em) con respecto a los parámetros poblacionales. Los valores de $p$ y q corresponden a 0,65 y 0,35 respectivamente, los mismos que representan la frecuencia con que los obreros cuentan con contrato escrito en una muestra piloto de 20 encuestas. Siguiendo el procedimiento metodológico, se tiene el siguiente resumen de las muestras y submuestras:

FICHA RESUMEN CÁLCULO MUESTRAL:

- Espacio geografico: Municipios Cercado, Quillacollo, Sacaba, Colcapirhua y Tiquipaya (Región Metropolitana)

- Macrounidades de análisis: Industrias de ramos alimentos, bebidas, textiles y curtiembres

- Unidades de análisis: Obreros y Obreras

- Tipo de muestreo: Probabilístico, estratificado por fijación ponderal según macrounidad

- Nivel de Confianza: 95\%

- Coeficiente Distribución: Z 1,96 - Z (cuadrática): 3,8416

- Población (N): 9673

- Probabilidad de Éxito (p): 0,65

- Probabilidad de fracaso (q): 0,35

- Error muestral (Em): 0,046 Em (Cuadrática): 0,002116

- Tamaño de la muestra (n): 337 (TOTAL ENCUESTAS)

$\mathrm{n} 1=118$ (ENCUESTAS ALIMENTOS)

$\mathrm{n} 2=84$ (ENCUESTAS BEBIDAS)

$\mathrm{n} 3=67$ (ENCUESTAS TEXTILES)

n4 $=67$ (ENCUESTAS CURTIEMBRES)

4. Se conoce como acumulación originaria de capital a proceso histórico de escisión(separación) entre el productor directo y sus medios de producción, un proceso necesario para la creación de las relaciones capitalistas de producción, que convierte a los productores directos en asalariados (Marx, 1985). En formaciones sociales como la de Bolivia, en la que el capitalismo no ha penetrado de forma más o menos homogénea en todos los sectores económicos, como sucedió en los países del capitalismo central, las formas parcelarias no capitalistas en el agro, perviven de manera simultánea a las formas capitalistas de producción; por eso un concepto como el de acumulación originaria de capital es útil para comprender y explicar un proceso contradictorio de reproducción de estas formas no capitalistas de producción dentro de las relaciones de producción capitalistas dominantes, a partir de diferentes vías (mercado de tierras, mercado de productos, de dinero, de trabajo, etc.) (Bartra, 1982).

5. El concepto de población excedente o sobrepoblación relativa (Marx,1985), hace referencia a una fuerza de trabajo que es excedente, en relación a las necesidades de reproducción y/o de acumulación de la producción capitalista. En el caso que nos ocupa, cuando en las formas parcelarias de producción, las familias ya no encuentran los medios de subsistencia necesarios, migran a las ciudades, si en ellas no encuentran trabajo en el sector capitalista, se convierten en población excedente o sobrepoblación, teniendo que refugiarse en un conjunto de actividades por cuenta propia. Se trata de un concepto que nos permite explicar y comprender el origen de esos importantes contingentes de población que ocupan las periferias de las urbes de países 
latinoamericanos, que constituyen el telón de fondo de los mercados de trabajo de la industria en estos países.

6. En Bolivia el Censo de Población y Vivienda, se realiza cada 10 años, es decir, que el próximo censo se efectuará en 2022, por lo que la información más actualizada, con la se cuenta, en términos censales es la de 2012.

7. El de la industria regional de alimentos bebidas, cueros y textiles, en el departamento de Cochabamba Bolivia.

8. En la era neoliberal (1985-2005), los flujos migratorios del campo a la ciudad, se incrementaron por la profundización de la crisis de la pequeña economía campesina; en la medida que la política de administración de tierras estuvo dirigida a apoyar un proceso de concentración y centralización de tierras; principalmente, en el sector capitalista del oriente, con instrumentos de legitimación como la Ley INRA, que estuvieron dirigidos a consolidar la orientación agroexportadora (mono productora) de las políticas neoliberales, con la legalización de la concentración de tierras productivas en el oriente del país, en manos de terratenientes (Ormachea, 2007, cit. por Grupo Llank'aymanta, 2008) y con la evolución negativa para los productos agrícolas, de los términos de intercambio, en relación a los productos industriales. Este deterioro de los términos de intercambio, profundizó la trasferencia de trabajo gratuito del sector agrícola parcelario (no capitalista) al sector capitalista; en este caso, mediante la producción de bienes de consumo baratos, para la reproducción de fuerza de trabajo asalariada. Se trata de una subvención que provoca el deterioro creciente de la capacidad de compra de la economía campesina, la que enfrenta una dificultad crónica para reproducirse, hecho que explica la creciente migración del campo a la ciudad y al exterior del país, que caracterizó el periodo.

9. En Cochabamba, como ilustración, después de la relocalización en 1985, 13.000 trabajadores, provenientes de los centros mineros, arribaron a los barrios periféricos. En el caso de un barrio representativo de la ciudad de Cochabamba (Villa Sebastián Pagador), la población se insertó a la matriz socioeconómica de la ciudad, a través de la realización de actividades económicas relacionadas con el comercio y servicios (restaurantes, hoteles, servicio doméstico, etc.) o como obreros en la construcción en la industria textil.

10. El coeficiente de industrialización de Bolivia, para 2019, da una idea del predominio primario exportador de su economía, con un índice de industrialización en promedio, del 16.7\%; y en el caso de Cochabamba, este índice alcanza al $20.6 \%$.

11. Modismo utilizado para referirse a tener contactos que faciliten la inserción laboral.

12. Si uno se detiene a reflexionar sobre la principal tendencia, respecto a modificaciones en la pertenencia de clase social de estos obreros, se ve que no existe una gran movilidad social, en relación a la generación de sus padres, las razones tienen que ver con las estrechas posibilidades de movilidad socioeconómica que encuentran los migrantes de primera generación al arribar a las ciudades ya sea del área rural y/o de los centros mineros.

13. Como el proceso de proletarización de estos obreros está asociado a una movilidad social ascendente, el poder consolidar su posición social como obreros, significa; también, la compra de un lote o de una casa a crédito en barrios obreros que se han ido formando alrededor de proyectos colectivos de fábrica, como testimonia uno de sus dirigentes: "Mucha gente no tenía vivienda, y vivía en alquiler y los salarios no alcanzaban. Entonces, eso fue quizás, la punta de lanza para poder iniciar esta búsqueda de terrenos y con mucha suerte pudimos armar un equipo y conseguir un terreno, 21 trabajadores se beneficiaron de este proyecto" (extracto de entrevista a un dirigente sindical de una empresa de alimentos, 2014).

14. El plan de la política económica de la revolución nacional (1955) tenía como orientación la necesidad de diversificar la economía nacional, caracterizada por la dependencia de la exportación de minerales, se trataba de un enfoque similar en muchos aspectos a la política de sustitución de importaciones de la CEPAL (Grebe, 2017). 


\section{RESÚMENES}

Entendido el territorio como una dimensión de la vida en el trabajo ; en este artículo, a partir de información sobre la configuración de los mercados de trabajo en la industria, en CochabambaBolivia, se busca explicar y comprender a estos mercados de trabajo, como espacios producidos socialmente, premisa y resultado de la praxis humana. En este sentido, se toma como hilo conductor a la trayectoria laboral de los trabajadores, en la que, las alternativas individuales o familiares se hilvanan con la disolución de las formas parcelarias de producción en el sector agrícola y con la dinámica de acumulación el capital en el espacio urbano. Si bien la movilidad de los trabajadores y la producción espacial de los mercados de trabajo son síntomas de procesos sociales generales, se rompe con una visión determinista, porque la práctica social que los produce es también, resultado de la dimensión subjetiva de los trabajadores.

A partir da compreensão do território como uma dimensão da vida no trabalho, procuramos, neste artigo, e a partir de dados sobre os mercados de trabalho na indústria, em CochabambaBolívia, explicar e compreender esses mercados como espaços socialmente produzidos, premissa e resultado da práxis humana. Neste sentido, a trajetória de trabalho dos trabalhadores é tida como um fio condutor em que as alternativas individuais ou familiares se entrelaçam com a dissolução das formas parcelares de produção no setor agrícola e com as dinâmicas de acumulação de capital no meio urbano. Embora a mobilidade dos trabalhadores e a produção espacial dos mercados de trabalho sejam sintomas de processos sociais gerais, esta rompe com uma visão determinista, pois a prática social que produz os sintomas é também resultado da dimensão subjetiva dos trabalhadores.

A partir de la compréhension du territoire en tant que dimension de la vie au travail, nous cherchons dans cet article, grâce à des données relatives aux marchés du travail dans l'industrie de Cochabamba-Bolivie, à expliquer et comprendre ces marchés du travail, en tant qu'espaces produits socialement, prémisse et résultat de la praxis humaine. En ce sens, la trajectoire de travail des travailleurs est tenue comme étant un fil conducteur autour duquel se tissent les alternatives individuelles ou familiales, avec la dissolution des formes parcellaires de production dans le secteur agricole et les dynamiques d'accumulation de capital en milieu urbain. Si la mobilité des travailleurs et la production spatiale des marchés du travail sont des symptômes de processus sociaux généraux, elles mettent en cause une vision déterministe puisqu'elles sont le résultat de pratiques sociales où intervient la dimension subjective des travailleurs.

In this paper, the territory is understood as a dimension of the life and the work. It based on information about the labor markets in the industry of Cochabamba-Bolivia, this paper has the purpose to explain the labor markets, as socially produced spaces, the premise and result of human praxis. In this sense, the workers' labor trajectory is taken as a common thread, in which the individual or family alternatives are woven together with the dissolution of the parcel forms of production in the agricultural sector and the dynamics capital accumulation in the urban space. Although the mobility of workers and the spatial production of labor markets are symptoms of general social processes, it breaks with a deterministic vision, because the social practice that produces them is also the result of the subjective dimension of workers. 
ÍNDICE

Mots-clés: parcours professionnels, marchés du travail, espace, armée de réserve industrielle, migration

Palabras claves: trayectorias laborales, mercados de trabajo, espacio, ejercito industrial de reserva, migración

Keywords: labor trajectories, labor markets, social space, industrial reserve army, migration Palavras-chave: trajetórias de trabalho, mercados de trabalho, espaço, exército industrial de reserva, migração

\section{AUTOR}

\section{TANIA AILLÓN GÓMEZ}

https://orcid.org/0000-0002-6529-7023

Instituo de Estudios Sociales y Economicos de la Universidad Mayor de San Simon; Grupo de Estudios del Trabajo Llank'aymanta

ledaillon@hotmail.com 